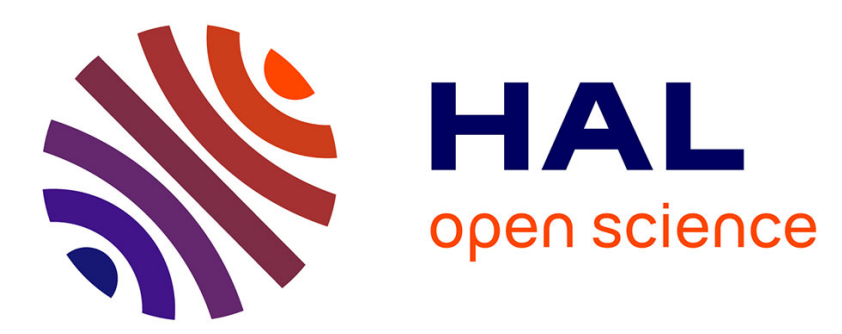

\title{
Guidelines for designing a realistic peripheral venous catheter insertion simulator: A literature review
}

\author{
K Torossian, S Benayoun, M Ottenio, A-C Brulez
}

\section{To cite this version:}

K Torossian, S Benayoun, M Ottenio, A-C Brulez. Guidelines for designing a realistic peripheral venous catheter insertion simulator: A literature review. Proceedings of the Institution of Mechanical Engineers, Part H: Journal of Engineering in Medicine, 2019, 10.1177/0954411919864786 . hal02186082

\section{HAL Id: hal-02186082 \\ https://hal.science/hal-02186082}

Submitted on 17 Jul 2019

HAL is a multi-disciplinary open access archive for the deposit and dissemination of scientific research documents, whether they are published or not. The documents may come from teaching and research institutions in France or abroad, or from public or private research centers.
L'archive ouverte pluridisciplinaire HAL, est destinée au dépôt et à la diffusion de documents scientifiques de niveau recherche, publiés ou non, émanant des établissements d'enseignement et de recherche français ou étrangers, des laboratoires publics ou privés. 
Guidelines for designing a realistic peripheral venous catheter insertion simulator:

A literature review

\author{
K. Torossian ${ }^{a, b} 1$, S. Benayoun ${ }^{a}$, M. Ottenio ${ }^{b}$ and A-C. Brulez ${ }^{c}$ \\ a Laboratoire de Tribologie et Dynamique des Systèmes, UMR CNRS 5513, Ecole Centrale de Lyon, 36 avenue Guy de Collongues, 69134 \\ Ecully cedex, France \\ b Univ Lyon, Université Claude Bernard Lyon 1, IFSTTAR, LBMC UMR_T9406, F69622, Lyon, France \\ c Laboratoire de Génie de la Fonctionnalisation des Matériaux Polymères, Institut Textile et Chimique de Lyon, 87 chemin des Mouilles, \\ 69134 Ecully cedex, France
}

\begin{abstract}
A literature review was conducted to develop more realistic medical simulators that better prepare aspiring health professionals to perform a medical procedure in vivo. Thus, this review proposes an approach that might assist researchers design improved medical simulators, particularly new materials that would enhance the sensation of touch for skin substitutes. By targeting the current needs in the field of simulation learning, we concluded that peripheral venous catheter insertion (PVCI) simulators lack realistic haptic feedback. Enhanced PVCI simulators will accelerate the mastery of the medical procedure, thus decreasing the number of failures in patients and costs related to this procedure.
\end{abstract}

Keywords: skin, veins, medical simulation, catheter insertion, substitutes, mechanical properties, indentation, perforation

\title{
1. Introduction
}

The medical procedure in which we are interested in developing a realistic simulator is peripheral venous catheter insertion ( $\mathrm{PVCl}$ ). $\mathrm{PVCl}$ is performed to administer intravenous therapy, such as medication and fluids, when the oral route is not available. Approximately $\mathbf{2 0 0}$ million catheters are placed in hospitalized patients each year in the United States ${ }^{1}$, making it the most common procedure performed by health professionals.

However, $\mathrm{PVCl}$ remains technically difficult to achieve, even for experienced nurses. Helm et al. ${ }^{2}$ observed a PVCl failure rate of $35 \%$ to $50 \%$, leading to a premature removal before the intended dwell time of the catheter. Several studies reported first attempt success in diverse patient populations for nurses with different experience levels. Overall, young nurses' success rates ranged from $44 \%$ to $76.9 \%$, while the success rates of more educated and experienced nurses ranged from $91 \%$ to $98 \%{ }^{3-5}$. Other researchers have reported a range of 2.18 and $2.35 \mathrm{PVCl}$ attempts to establish a patent peripheral intravenous (IV) site ${ }^{67}$.

Several patient factors that contribute to insertion failure have been described in the literature ${ }^{8}$ : age; patient size; limited and suitable veins contributing to a difficult intravenous access; a previous history of failed attempts and recent hospital admission; diabetes; intravenous drug use; cancer diagnosis and recent chemotherapy; and vasoconstriction of veins caused by patient anxiety. However, the experience of health professionals mitigates the effects of these patient factors.

\footnotetext{
${ }^{1}$ Corresponding author: Laboratoire de Tribologie et Dynamique des Systèmes, UMR CNRS 5513, Ecole Centrale de Lyon, 36 Avenue Guy de Collongues, 69134 Ecully cedex, France.

E-mail address: kevin.torossian@ec-lyon.fr
} 
Nevertheless, young health professionals are rarely able to accumulate a sufficient amount of practical experience to tackle their first in vivo PVCl with success. Researchers have developed multiple generations of image-guided robots that can autonomously perform a venipuncture to address this issue ${ }^{9}{ }^{10}$, but these instruments may be used only in few health centers and do not replace trained nurses, particularly in critical situations.

Therefore, numerous public health authorities in developed countries have been recommending the use of medical simulators to better prepare students in medical fields to perform their first in vivo medical procedure and to minimize the risks associated with patient safety for several years ${ }^{11}$. Many types of simulators ${ }^{12}{ }^{13}$ have been developed to meet the increasing demand of hospitals for simulation learning, such as part-task trainers or manikins, among others. However, all types of simulators currently in use have limitations in terms of realistic haptic feedback. For some procedures, the force is the main consideration, such as epidural simulation ${ }^{14}{ }^{15}$. For procedures such as $\mathrm{PVCl}$, the sensation of touch perceived by the practitioner is also very important. The ability to localize the superficial veins of the anatomical zone is one of the keys to a successful PVCI.

Generally, medical simulators facilitate a more or less immersive experience due to the potential step-by-step application of the medical protocol while interacting with the environment and the practitioner. The main goals of researchers aiming to design a more realistic $\mathrm{PVCl}$ simulator are to enhance its interactions with the practitioner or its representativeness. The interactions are enhanced via computer-based simulators, which are not developed for venipunctures or via specific simulation techniques. In our case, we chose to focus on methods to enhance the anatomical and mechanical representativeness of the $\mathrm{PVCl}$ simulator. Therefore, different parameters that the simulator should respect were identified (Figure 1): the representativeness of the anatomical region, geometry of soft tissues, skin surface properties, realistic deformation during palpation, and realistic puncture force.

\section{[Insert Figure 1]}

Figure 1: Identified parameters influencing simulation-based learning for PVCI

As a result, this review aims to highlight the guidelines needed to design a more realistic $\mathrm{PVCl}$. The targeted simulator should allow a better immersion for practice, and thus the user would ideally forget about the simulator. We first focused our attention on the interactions between the practitioner and the patient when locating the veins to address this challenge, prompting the need for a review of the geometrical parameters of skin and veins. We reviewed the tribological studies performed on skin. These data help improve the touch sensation for the practitioner. Then, we were interested in the mechanical tests conducted on the skin that are relevant to the medical procedure, namely, perforation and indentation tests. Finally, several tissue-mimicking substitutes that have been developed to reproduce human skin friction, deformation and perforation behaviors are briefly described.

\section{Patient - Practitioner interactions}

According to their degree of resemblance with reality, simulation devices are categorized into either low or high fidelity. The most common type of simulator used for PVCl training is part-task trainers that replicate only part of the environment, for instance, the skin and the veins of the 
forearm. Although these types of simulators are considered low fidelity, the emergence of pads that are strapped on a specific anatomical zone enable the practitioner to perform hybrid simulation (Figure 2).

\section{[Insert Figure 2]}

Figure 2: Different part-task trainers simulators: a) IV practice arm and b) strap-on venipuncture trainer

This simulation technique consists of combining part-task trainers with standardized patients and includes the previously lacking communicative aspect, thus becoming a high-fidelity simulation. Hybrid simulation helps improve students' confidence in procedural skills ${ }^{16}$. Other authors, such as Wilfong et al. ${ }^{17}$ and Keleekai et al. ${ }^{18}$, have concluded that simulation-based training decreased the number of patient complications while increasing the knowledge, skills and confidence of nurses.

The benefits and disadvantages of both types of simulators are presented in Table 1.

Table 1 Comparison of IV practice arm and strap-on venipuncture trainers

\begin{tabular}{lcccccc}
\hline & Anatomy & $\begin{array}{c}\text { Tissue } \\
\text { geometry }\end{array}$ & $\begin{array}{c}\text { Patient- } \\
\text { Practitioner } \\
\text { interactions }\end{array}$ & $\begin{array}{c}\text { Mechanical } \\
\text { properties }\end{array}$ & $\begin{array}{c}\text { Surface } \\
\text { properties }\end{array}$ & Cost \\
\hline IV practice arm & + & - & - & - & - & -- \\
IV practice pad & - & - & ++ & - & - & + \\
\hline
\end{tabular}

Although the anatomical representativeness of practice arms allows the practitioner to spatially visualize a human arm, the patient-practitioner interactions are more realistic in trainers employing strapped pads. In both types of simulators, the mechanical and surface properties of the currently used polymers do not adequately recapitulate those of the skin and veins, and we noted that the geometrical parameters, such as skin thickness and vein diameters, are not representative. Overall, strapped pads cost less due to the simplified design.

\subsection{Representativeness of the anatomical zone and geometry}

Researchers must first define the targeted anatomical zone to develop a realistic medical simulator. In our case, we chose to study the ventral side of the forearm between the antecubital fossa and the wrist. This location was chosen because catheters are not usually inserted in the antecubital fossa to avoid disturbing the motion of the patient's arm at the elbow. The dorsal surface of the hand has also been neglected because it is a highly innervated region, causing harm to the patient during puncture. Nevertheless, we recognize that catheters are sometimes inserted into the veins located on the dorsal surface of the hand to preserve the venous network in case of failure, particularly in elderly persons. 
Catheters placed in the antebrachial zone are inserted into the superficial veins, which are located in the hypodermis and lie on the underlying muscle fascia. The superficial vein network of the forearm is composed of three main veins: the basilic vein, the median antebrachial vein and the cephalic vein (Figure 3).

\section{[Insert Figure 3]}

Figure 3: Superficial venous system of the upper limbs ${ }^{19}$

After narrowing the anatomical zone to the volar forearm skin and the aforementioned superficial veins, part of our literature review is devoted to identifying geometrical parameters, such as the thickness of each skin layer, which is known to vary as a function of age, body zone or hydration ${ }^{20}$. Indeed, the skin is a complex, multilayered tissue composed of an external superficial layer, the stratum corneum, under which lies the viable epidermis, the dermis and the hypodermis. Veins have a three-layered wall composed of an internal endothelium surrounded by a thin layer of muscle fibers that is surrounded by a layer of connective tissue (Figure 4).

The thickness and the diameter of the superficial veins have also been determined to enable suitable phantom veins to be manufactured.

\section{[Insert Figure 4]}

\section{Figure 4: Schematic showing a cross section of: a) the human skin structure and b) vein structure}

Lee \& Hwang ${ }^{21}$ performed ex vivo measurements to measure the dermal and epidermal thickness at 28 anatomical sites of 452 cadavers using microscopes and micrometers. The same approach was subsequently adopted by Hwang et al. ${ }^{22}$, who also measured the hypodermis thickness. In vivo measurements of the thickness of the dermis and hypodermis have also been conducted on the volar forearm using ultrasound images ${ }^{23-26}$.

More recently, the in vivo epidermal thickness was measured by Maiti et al. ${ }^{27}$ using optical coherence tomography (OCT). In the same study, a literature review of the epidermal thickness obtained using various techniques was also reported. Regarding the superficial veins, Kiray et al. ${ }^{28}$ and Shima et al. ${ }^{29}$ performed ex vivo measurements to obtain the inner diameter and the thickness of the cephalic and basilic veins. Ultrasound measurements were used by Irfan et al. ${ }^{30}$ to show alterations in the inner diameters of superficial veins of living subjects according to changes in ambient temperature. This finding also emphasizes the fact that in vivo measurements of vein diameters are substantially influenced by blood pressure.

The relevant geometrical results for the development of the PVCl simulator are listed in Table 2 and Table 3. 
Table 2 Thickness of the different skin layers in the forearm reported in the literature

\begin{tabular}{|c|c|c|c|c|}
\hline \multirow{2}{*}{ References } & \multirow{2}{*}{$\begin{array}{l}\text { Tissue } \\
\text { state }\end{array}$} & \multicolumn{3}{|c|}{ Thickness $(\mathrm{mm})$ (mean \pm SD or range) } \\
\hline & & Epidermis & Dermis & Hypodermis \\
\hline Lee \& Hwang ${ }^{21}$ & Ex vivo & $0.074 \pm 0.025$ & $1.02 \pm 0.21$ & - \\
\hline Hwang et al. ${ }^{22}$ & Ex vivo & $0.042 \pm 0.026$ & $0.991 \pm 0.318$ & $1.913 \pm 1.066$ \\
\hline Hendriks et al. ${ }^{23}$ & In vivo & - & $1.350 \pm 0.1$ & 0.81 \\
\hline Diridollou et al. ${ }^{24}$ & In vivo & - & $1.16-1.23$ & $1.10-1.21$ \\
\hline Escoffier et al. ${ }^{25}$ & In vivo & - & $0.55-0.88$ & - \\
\hline Gennisson et al. ${ }^{26}$ & In vivo & - & $1.140 \pm 0.2$ & $1.59 \pm 0.79$ \\
\hline \multirow{2}{*}{ Maiti et al. ${ }^{27}$} & In vivo & $0.099 \pm 0.009$ & - & - \\
\hline & Review & $0.053-0.128$ & - & - \\
\hline
\end{tabular}

\begin{tabular}{|c|c|c|c|c|c|c|c|}
\hline \multirow{2}{*}{ References } & \multirow{2}{*}{$\begin{array}{l}\text { Tissue } \\
\text { state }\end{array}$} & \multicolumn{3}{|c|}{$\begin{array}{l}\text { Inner diameter }(\mathrm{mm}) \\
\quad(\text { mean } \pm \mathrm{SD})\end{array}$} & \multicolumn{3}{|c|}{$\begin{array}{l}\text { thickness }(\mathrm{mm}) \\
(\text { mean } \pm \mathrm{SD})\end{array}$} \\
\hline & & Cephalic & Basilic & Median & Cephalic & Basilic & Median \\
\hline Kiray et al. ${ }^{28}$ & Ex vivo & $2.04 \pm 1.24$ & $1.35 \pm 0.6$ & - & $0.33 \pm 0.10$ & $0.29 \pm 0.06$ & - \\
\hline Shima et al. ${ }^{29}$ & Ex vivo & $1.7 \pm 1.0$ & $3.2 \pm 1.4$ & $2.0 \pm 1.2$ & - & - & - \\
\hline Irfan et al. ${ }^{30}$ & In vivo & $3.1 \pm 0.9$ & $5.1 \pm 1.3$ & - & - & - & - \\
\hline
\end{tabular}

The region between the wrist and the elbow has also been observed using different imaging techniques, such as infrared imaging ${ }^{31}$, ultrasound imaging ${ }^{32}$ and optoacoustic tomography ${ }^{33}$, to capture the depth of superficial veins. The depth ranged from $0.9 \mathrm{~mm}$ to $2 \mathrm{~mm}$, consistent with the fact that superficial veins are located in the hypodermis layer of the skin and lie on the muscle fascia.

\subsection{Skin surface properties}

Objective representations of touch perception, such as smoothness, remain particularly difficult. Therefore, Kawazu et al. ${ }^{34}$, among other authors, proposed an objective representation of touch 
perception based on the values of the arithmetical roughness ( $\mathrm{Ra}$ ) and kinetic friction coefficient $\left(\mu_{k}\right)$. Numerous tribological tests have been conducted on human skin to develop suitable skin substitutes for medical research, textile exploitation or cosmetics.

Derler et al. ${ }^{35}$ reviewed the available experimental results for skin friction coefficients by comparing results obtained using diverse measurement techniques at different anatomical sites with various skin conditions. Indeed, the skin friction coefficient varies according to the state, namely, a dry or a wet state. As shown in the study by Pailler-Mattei et al. ${ }^{36}$, the lipid film present on the skin surface is responsible for the adhesion properties of the skin due to capillary phenomena which are the main contributors to dry human skin friction, according to Adams et al. ${ }^{37}$ and Sivamani et al. ${ }^{38}$.

In addition to skin condition, studies have examined the effect of age, gender and the anatomical zone. Discrepancies have been reported in the literature regarding the age and gender dependence of the skin friction coefficient. Some authors did not report effects of age and gender ${ }^{39-41}$, whereas other authors, such as Elsner et al. ${ }^{42}$, observed higher friction coefficients for the forearm skin of younger women. Zhu et al. ${ }^{43}$, who performed tests on a large Chinese population, also concluded that gender and age affected their results.

Cua et al. ${ }^{44}$ performed tribological experiments on eleven anatomical zones and highlighted a dependence of the skin friction coefficient on the anatomical region. The authors suggested that one possible factor is sebum secretion.

Following the identification of factors that potentially influence the skin friction coefficient, we are able to identify which skin kinetic coefficient observed in the literature is useful for the development of a material for the top surface of the $\mathrm{PVCl}$ simulator. Indeed, when performing a $\mathrm{PVCl}$, the practitioner does not modify the skin condition, at least during the palpation phase of the procedure. Therefore, the targeted studies performed tests on dry, untreated or normal, volar forearm skin. For representativeness and consistency with typical loads applied for roughness assessments using human fingers ${ }^{45}$, only studies that performed tests on more than three subjects with a normal force greater than $0.4 \mathrm{~N}$ were selected (Table 4).

Table 4 Dry forearm skin kinetic friction coefficient $\left(\mu_{k}\right)$ reported in the literature

\begin{tabular}{llcl}
\hline References & Sample size & $\mu_{k}(-)($ mean \pm SD) & $\begin{array}{l}\text { Normal force (N) (mean } \\
\pm \text { SD or range) }\end{array}$ \\
\hline Elsner et al. $^{42}$ & 44 & $0.48 \pm 0.01$ & 1.96 \\
Cua et al. $^{44}$ & 29 & $0.26 \pm 0.01$ & 1.96 \\
Derler et al. $^{45}$ & 12 & $0.415 \pm 0.124$ & $0.2-15$ \\
Gupta et al. $^{46}$ & 41 & $0.41 \pm 0.08$ & 0.49 \\
Zhang et al. $^{47}$ & 10 & $0.46 \pm 0.10$ & 0.98 \\
El-Shimi & & & \\
\hline
\end{tabular}


The remaining mean values for the kinetic friction coefficient of dry forearm skin reported in the literature range from 0.26 to 0.53 . However, this interval must be considered cautiously because several factors influence the results, such as differences in the applied normal load, the use of different measurement techniques and individual differences.

In addition to the friction coefficient, the touch properties of materials are also characterized by roughness parameters. Maiti et al. ${ }^{27}$ performed measurements on one human subject to assess human skin roughness parameters ( $\mathrm{Ra}$, arithmetic mean roughness and $\mathrm{Rz}$, mean depth roughness), and the values were compared to the literature. The measurements were obtained using OCT at different forearm angles $\left(90^{\circ}\right.$ flexion and $180^{\circ}$ full extension). Based on their measurements, Maiti et al. observed that $R a$ and $R z$ decreased from $14.2 \pm 2.6 \mu \mathrm{m}$ and $75.7 \pm 16.7 \mu \mathrm{m}$ to $8.4 \pm 2.2 \mu \mathrm{m}$ and $38.4 \pm 11.0 \mu \mathrm{m}$, respectively, when the arm was fully extended, resulting in a non-negligible mean reduction of $40.7 \%$ and $49.3 \%$, respectively. As the patient's arm is extended during a $\mathrm{PVCl}$, the results reported by Maiti et al. ${ }^{27}$ prompted us to perform a literature review to identify results for Ra and $\mathrm{Rz}$ in extended arms. However, to our knowledge, no other publications performed roughness measurements on fully extended arms. Nonetheless, the review performed by Maiti et al. ${ }^{27}$ allowed us to visualize results for flexed arms (Table 5).

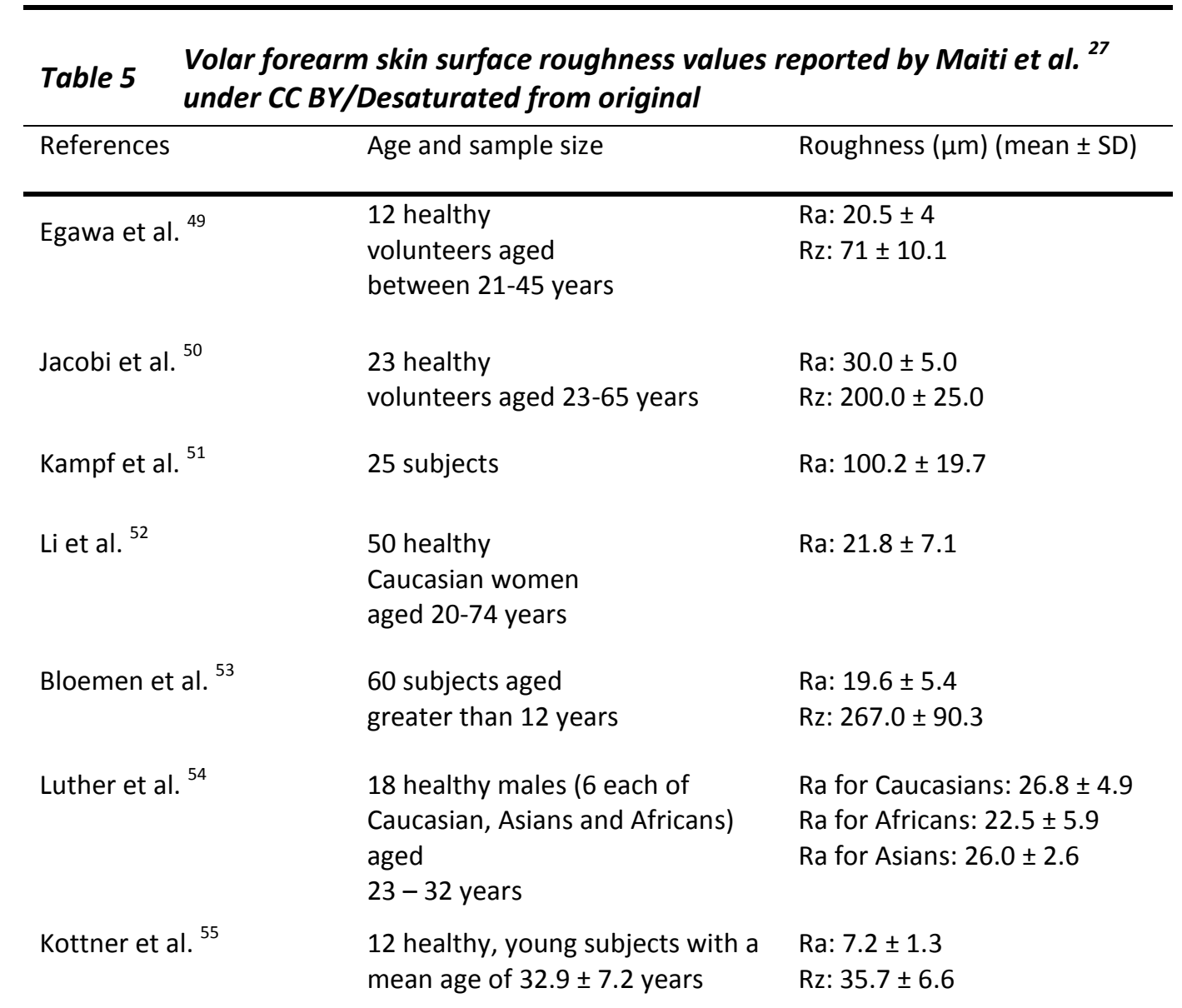


Trojahn et al. ${ }^{56}$
8 subjects each of young (31-37

years) and aged (74-79 years)

Caucasian female volunteers
Ra for young: $38.2 \pm 4.3$

Ra for aged: $46.5 \pm 7.1$

By applying talcum powder on the skin, El-Shimi ${ }^{48}$ and Comaish \& Bottoms ${ }^{57}$ observed a decrease in the friction coefficient; however, wetting the talcum powder increased the friction coefficient. Powder is often applied during the process of manufacturing skin equivalents to artificially decrease the friction coefficient of the developed polymers, which are quite sticky. However, in $\mathrm{PVCl}$, the sterilization phase uses disinfectant solutions such as chlorhexidine or povidone-iodine based solutions ${ }^{58} 59$ to wet the puncture site, thus potentially preventing the use of powders to decrease the friction coefficient of the processed polymers.

\section{Mechanical properties of soft tissues related to PVCI}

Regarding the mechanical aspect of the simulator, the mechanical behavior that must be represented by the $\mathrm{PVCl}$ simulator is a coupled response corresponding to the mechanical properties of both the skin and the superficial veins.

Those two living tissues, in addition to the epidermis, are both mainly composed of an arranged network of collagen fibers and elastic fibers embedded in a ground substance ${ }^{60}$. This structured network renders soft living tissues as non-linear ${ }^{61}$, viscoelastic ${ }^{62}{ }^{63}$, anisotropic ${ }^{64}$, naturally stressed 6566 and nearly incompressible materials ${ }^{67} 68$.

Subsequently, the practitioner's gesture has been analyzed and decomposed into the following four main phases, in addition to the hygienic part of the procedure, to identify what types of mechanical processes were applied on the soft tissues and obtain a better understanding of the mechanical behavior of skin and veins during PVCl:

- palpation to locate the vein to puncture,

- stretching of the skin by applying a normal and a tangential force to prevent the vein from rolling,

- puncture of the skin and the vein, and

- catheter placement and withdrawal of the needle.

Thus, we decided to focus our attention on the palpation and perforation steps of the medical procedure.

\subsection{Palpation step of the medical procedure}

The palpation technique employed by the practitioner during the procedure allows him/her to visualize the location of the blood vessels and feel their "elasticity". Palpation is compared to an indentation test, which is performed at different scales. For multilayered materials such as human skin, the scale choice is very important and determines the need to evaluate a global mechanical response or surface properties alone. According to Payne ${ }^{69}$ who realized indentation tests on human skin, there is no influence of subcutaneous fat tissues or underlying tissues for displacements which 
are not exceeding $700 \mu \mathrm{m}$. By conducting a literature review of the indentation tests performed on the volar forearm skin, van Kuilenburg et al. ${ }^{70}$ also noted that the length scale had a decisive influence on the elastic moduli of the skin. The authors suggest the use of the effective modulus, also known as the apparent or equivalent elastic modulus, to account for the multilayered and nonhomogeneous structure of the skin.

The practitioner applies a sufficiently large displacement to feel the underlying tissue, including the superficial veins, thus exceeding the value of $700 \mu \mathrm{m}$ to identify a suitable vein for PVCl. Additionally, the patient is asked to clench his/her fist during the procedure to allow a better visualization of the venous network. Zheng et al. ${ }^{71}$ reported the influence of velocity and muscular contraction on the results of indentation tests on the dorsal part of the forearm. The authors obtained a value of $14 \mathrm{kPa}$ for the Young's modulus at rest, which increased to $59 \mathrm{kPa}$ with muscular contraction. The same conclusion was reported more recently by livarinen et al. ${ }^{72}$, who measured an elastic modulus of 210 $\mathrm{kPa}$ on the inner forearm at rest, which increased to 446 and $651 \mathrm{kPa}$ under flexor and extensor loading of the muscle, respectively.

The majority of indentation tests reported in the literature avoided high displacements in the interest of targeting the mechanical response of skin and more specifically the response of the dermis. Although the epidermis is stiffer than the dermis due to the outermost layer of the epidermis, the stratum corneum ${ }^{73}$, the contributions of the epidermis to the global properties of the skin are often neglected due to its low thickness ${ }^{65}$. This observation was confirmed by Dikstein \& Hartzshtark ${ }^{74}$, who studied the effects of the different layers of forehead skin on the results of indentation tests conducted at low pressure in vivo. Moreover, the dermis is the main structure of the skin; hence, the dermis and its components predominantly participate in the mechanical behavior of $\operatorname{skin}^{62} 75$.

However, in the PVCl procedure, results of the indentation tests, which provided a global mechanical parameter of the skin by solely restricting the mechanical behavior of the skin to the dermis, are not sufficient to facilitate the development of a realistic simulator. In fact, the muscle contraction and the hypodermis, which allow the veins roll with applied loads, must be considered. Therefore, the goal of this part of the literature review conducted in the present study was to identify studies that performed macro-indentation experiments or numerical simulations using a multilayered skin model.

Pailler-Mattei et al. ${ }^{76}$ performed indentation tests on the volar forearm of 10 subjects using a conical steel indentor. The skin was first considered a thin elastic layer on a rigid substrate. At approximately $1.5 \mathrm{~mm}$, the average Young's modulus of the skin increased as the indentation depth increased from 12 to $18 \mathrm{kPa}$ because depth penetration went as far as $4 \mathrm{~mm}$, taking into account the influence of underlying tissues. Three mechanical elastic models were then used to account for the influence of the muscle, thus isolating the Young's modulus of the skin. The models showed consistent results with each other and the reduced skin modulus remained constant, ranging between 4.5 to $8 \mathrm{kPa}$, depending on the model.

Subsequently, Pailler-Mattei et al. ${ }^{76}$ replaced their previous model with a mechanical model composed of the dermis and hypodermis on a rigid substrate to account for the contributions of the stated layers. The mechanical model is equivalent to an assembly of three springs with different stiffnesses connected in series. Using a derived equation proposed for the mechanical model, which was comprised of the Young's modulus of each layer, the authors were able to identify a set of parameters to fit their analytical results to the experimental curves. 
Abellan et al. ${ }^{77}$ used an inverse method combined with a finite element model that reproduced contactless indentation tests on the volar forearm. The mechanical parameters were optimized to fit the numerical simulation results to the experimental curve, thus allowing them to obtain the Young's modulus of each skin layer. Each layer was considered an elastic, isotropic and compressible material.

Tran et al. ${ }^{78}$ combined indentation tests performed on the dorsal forearm of a young man with magnetic resonance imaging (MRI) and an inverse method to reveal the mechanical parameters of all skin layers. The epidermis, dermis and muscle were modeled by an incompressible Neo-Hookean model, while the hypodermis was considered nearly incompressible. The maximum displacement obtained was $3.02 \mathrm{~mm}$.

Subsequently, Tran et al. ${ }^{79}$ published another study using the same experimental setup, but considered the skin layers and the underlying muscle as slightly compressible materials.

The results obtained for multilayered models of skin during indentation tests are presented in Table 6.

\begin{tabular}{|c|c|c|c|}
\hline $\begin{array}{l}\text { Your } \\
\text { mult }\end{array}$ & $\begin{array}{l}\text { modulus of skin lay } \\
\text { er models }\end{array}$ & obtained from inde & ts using \\
\hline References & Model & Anatomical zone & $\begin{array}{l}\text { Identified } \\
\text { parameters* }[\mathrm{kPa}]\end{array}$ \\
\hline \multirow{2}{*}{ Pailer-Mattei et al. ${ }^{76}$} & $\begin{array}{l}\text { One-layer } \\
\text { linear elastic model }\end{array}$ & In vivo volar forearm & $E_{\text {skin }}=4.5-8$ \\
\hline & $\begin{array}{l}\text { Two-layer + muscle } \\
\text { linear elastic model }\end{array}$ & In vivo volar forearm & $\begin{array}{l}E_{D}=35 \\
E_{H}=2 \\
E_{M}=80\end{array}$ \\
\hline Abellan et al. ${ }^{77}$ & $\begin{array}{l}\text { Four-layer } \\
\text { linear elastic model }\end{array}$ & In vivo volar forearm & $\begin{array}{l}E_{S C}=1.4 e 4 \\
E_{V E}=60 \\
E_{D}=50 \\
E_{H}=2\end{array}$ \\
\hline Tran et al. ${ }^{78}$ & $\begin{array}{l}\text { Three-layer + muscle } \\
\text { Neo-Hookean model }\end{array}$ & In vivo dorsal forearm & $\begin{array}{l}C_{10 E}=1.5 e 3 \\
C_{10 D}=310 \\
C_{10 H}=8.2 \\
C_{10 M}=73\end{array}$ \\
\hline Tran et al. ${ }^{79}$ & $\begin{array}{l}\text { Three-layer + muscle } \\
\text { Neo-Hookean model }\end{array}$ & In vivo dorsal forearm & $\begin{array}{l}C_{10 E}=120 \pm 60 \\
C_{10 D}=1.11 e 3 \pm 90 \\
C_{10 H}=0.42 \pm 0.50 \\
C_{10 M}=3.64 \pm 0.26\end{array}$ \\
\hline
\end{tabular}

* SC : stratum corneum, VE : viable epidermis, D: dermis, $\mathrm{H}$ : hypodermis, $\mathrm{M}$ : muscle

Other studies have performed indentation tests on the ventral side of the forearm ${ }^{80-84}$, for which the skin's elastic moduli ranged from 5.4 to $17.7 \mathrm{kPa}$; however, these results only represented the mechanical response of the dermis. The penetration depth of the indenter was often too small to 
determine the effects on all the layers involved during the palpation phase of a PVCl. These results are still useful for assessing the mechanical properties of the dermis layer of the $\mathrm{PVCl}$ simulator.

According to Pailler-Mattei et al. ${ }^{81}$ and Jachowicz et al. ${ }^{83}$, among other researchers, gender and age affect the elastic moduli of the skin. Regarding the effect of hydration, only tests performed at the micro-scale are strongly influenced by this parameter because of the presence of the stratum corneum, which is strongly dependent on the environmental temperature and relative humidity ${ }^{70} 85$. Finally, the majority of results obtained by performing indentation tests on skin were derived using the method reported by Oliver and Pharr ${ }^{86}$. According to Geerligs et al. ${ }^{87}$, while this method easily provides an estimate of the skin stiffness, it is only valid for materials with a completely elastic response upon unloading, which is not the case for the non-elastic behavior of the skin.

Other models have been used to model skin, such as exponential, polynomial, hyperelastic or quasi linear viscoelastic models. One of the most representative models is the Gasser-Ogden-Holzapfel ${ }^{88}$ model that considers the anisotropic behavior of skin and has the following strain energy density:

$$
W=\frac{\mu}{2}\left(I_{1}-3\right)+\mu \sum_{i=1,2} \frac{k_{i 1}}{2 k_{i 2}}\left(e^{k_{i 2}\left[\operatorname{tr}\left(H_{i} C\right)-1\right]^{2}}-1\right)
$$

where $I_{1}=\operatorname{tr}(C)$, with $C$ representing the right Cauchy-Green strain tensor. 0 is a positive material constant. The index $i$ is used to separately describe the mechanical behaviors of elastic and collagen fibers. $k_{i 1}$ and $k_{i 2}$ are dimensionless stiffness parameters. $H_{1}$ and $H_{2}$ are structure tensors defined as $H_{i}=\kappa_{i} I+\left(1-3 \kappa_{i}\right) a_{1} * a_{2}$.

A more easily implementable model that is frequently used to describe the behavior of the skin is the isotropic hyperelastic Ogden model ${ }^{89}$ :

$$
W=\sum_{i=1}^{N} \frac{2 \mu_{i}}{\alpha_{i}^{2}}\left(\lambda_{1}^{\alpha_{i}}+\lambda_{2}^{\alpha_{i}}+\lambda_{3}^{\alpha_{i}}-3\right)
$$

where $\lambda_{1}, \lambda_{2}$ and $\lambda_{3}$ are the principle stretch ratios, $\alpha$ is a strain hardening exponent and 2 represents the shear modulus.

The review by Joodaki \& Panzer ${ }^{90}$ emphasized that these models, in addition to other models, have mainly been used to describe the behavior of the skin during extension.

\subsection{Perforation step of the procedure}

Several factors must be considered when evaluating and analyzing the perforation of living tissues. By measuring the force required to perforate cadaver skin with a knife, Knight ${ }^{91}$ concluded that the sharpness of the knife was the major factor. This observation was subsequently confirmed by Green ${ }^{92}$. Knight also noted that the naturally pre-stressed state of the skin decreased the force required to puncture soft tissues, confirming the conclusion of Figge $\&$ Barnett ${ }^{93}$, who performed perforation tests with a needle on pre-stressed and loosened cadaver skin. 
According to Shergold \& Fleck ${ }^{94}$, the difference in the force needed to puncture pre-stressed and loosened cadaver skin may be attributed to the fact that the needle compresses the loosened skin against the underlying muscle fascia, which increases the resulting force. However, we note inconstancies in this statement. Frick et al. ${ }^{95}$ who performed perforation tests on excised sheep skin observed that more force was needed to puncture pre-stressed sheep skin.

Knight ${ }^{91}$ and Green ${ }^{92}$ also revealed the influence of the impact velocity on the force required to perforate the skin. Indeed, the required force decreased as velocity increased; nevertheless, discrepancies in this parameter have been noted. In the study by Frick et al. ${ }^{95}$, the perforation did not decrease when the velocity was increased, while Brett et al. ${ }^{14}$ noticed a decrease in the perforation force when increasing the impact velocity for tests performed on the membrane protecting the epidural cavity. Other authors reported the same observations as Brett et al., such as Heverly et al. ${ }^{96}$ and Mahvash \& Dupont ${ }^{97}$, who observed ex vivo perforation on porcine heart for velocities ranging from 5 to $250 \mathrm{~mm} / \mathrm{s}$ and from 1 to $100 \mathrm{~mm} / \mathrm{s}$. As shown in the study by Heverly et al. ${ }^{96}$, the force required to puncture the skin does not decrease further after a certain velocity value.

Shergold \& Fleck ${ }^{94}$ modeled skin as an Ogden material to develop a model capable of predicting the perforation force of soft solids using flat-bottomed and sharp-tipped cylindrical punches. In their study, the factors exerting the greatest effects on the puncture of soft solids were the geometry of the penetrator, the type of tissue and loading parameters, such as the impact velocity and the degree of pre-stretch of the tissue.

Okamura et al. ${ }^{98}$ characterized needle insertion by decomposing the total force through a summation of stiffness, friction and cutting forces. The stiffness force occurs before puncture, while friction and cutting forces occur after puncture:

$$
f_{\text {needle }}(x)=f_{\text {stiffness }}(x)+f_{\text {friction }}(x)+f_{\text {cutting }}(x)
$$

Regarding a classical needle insertion, the observations reported by Barbé et al. ${ }^{99}$, which are based on a perforation force curve obtained by Maurin et al. ${ }^{100}$, are representative of the process that occurs during a $\mathrm{PVCl}$, as described below (Figure 5).

- First, the needle pushes the tissue surface, which becomes deformed. Prior to perforation, the load applied to the soft tissue is characterized by a viscoelastic interaction between the needle and the tissue and is related to an indentation test. In practice, the viscoelastic phase is often minimized by the practitioner during the insertion by piercing the organs with an abrupt motion of the needle ${ }^{96}$.

- When the force applied by the needle to the tissue reaches a particular energetic threshold ${ }^{96}$, the needle penetrates the tissue. While the needle is inserted by cutting the tissue, the friction forces attract the surrounding tissue along the needle shaft.

- Then, during the extraction phase of the needle, the tissue is again attracted by the motion direction. 


\section{[Insert Figure 5]}

Figure 5: Standard force vs. time perforation curve during the insertion and withdrawal of a needle in soft tissues

However, in a PVCl, the needle is surrounded by a catheter, for which the friction coefficient modifies the evolution of the perforation force curve during the insertion phase ${ }^{101}{ }^{102}$, thus obtaining distinctive force peaks. Moreover, as the catheter is maintained in the superficial veins to allow the administration of intravenous fluids, the needle is retracted without contact with the surrounding tissue, and the third phase described above would not be visible on perforation graphs for this specific procedure.

Our literature review of the perforation step of a $\mathrm{PVCl}$ allowed us to collect results for peak loads obtained during the puncture of skin at different anatomical sites, as well as polymers and animal skin. The experimental conditions were also noted. In addition to velocity, angle insertion also affects peak insertion forces ${ }^{103}$. These values will serve as a basis for comparison with future investigations of the gesture of the practitioner during the procedure (Table 7).

\section{Table 7 Overview of published results for peak perforation during needle insertion in soft tissues}

\begin{tabular}{|c|c|c|c|c|c|c|}
\hline References & Materials & Catheter & $\begin{array}{l}\text { Insertion } \\
\text { velocity } \\
(\mathrm{mm} / \mathrm{s})\end{array}$ & $\begin{array}{l}\text { Insertion } \\
\text { angle } \\
\left({ }^{\circ}\right)\end{array}$ & $\begin{array}{l}\text { Perforator } \\
\text { diameter } \\
(\mathrm{mm})\end{array}$ & $\begin{array}{l}\text { Force peak } \\
\text { (N) (mean } \pm \\
\text { SD or range }\end{array}$ \\
\hline Abolhassani et al. ${ }^{104}$ & $\begin{array}{l}\text { Turkey skin } \\
\text { and tissue }\end{array}$ & No & $5-20$ & - & 1.02 & $0.96 \pm 0.063$ \\
\hline Suzuki et al. ${ }^{102 \mathrm{a}}$ & Polyethylene & Yes & 3.3 & $30-45$ & $\begin{array}{l}0.09 \\
1.02\end{array}$ & $\begin{array}{l}0.12 \\
0.27\end{array}$ \\
\hline \multirow[b]{3}{*}{ Eriksson et al. ${ }^{101 \mathrm{~b}}$} & Lamb skin & & 1.67 & 30 & - & $\begin{array}{l}3.4 \pm 0.6 \\
4.1 \pm 0.2\end{array}$ \\
\hline & Latex & & 0.83 & 90 & - & 0.2 \\
\hline & $\begin{array}{l}\text { In vivo human } \\
\text { skin and } \\
\text { dorsal hand } \\
\text { vein }\end{array}$ & Yes & - & $15-20$ & - & $\begin{array}{l}2.4 \pm 0.9 \\
3.5 \pm 1.2\end{array}$ \\
\hline Shergold \& Fleck ${ }^{105}$ & $\begin{array}{l}\text { In vivo human } \\
\text { forearm skin }\end{array}$ & No & 1 & 90 & $\begin{array}{l}0.3 \\
0.6\end{array}$ & $\begin{array}{l}0.6 \\
0.8\end{array}$ \\
\hline Podder et al. ${ }^{106}$ & $\begin{array}{l}\text { Perineal area } \\
\text { in vivo male } \\
\text { skin }\end{array}$ & No & 300 & 90 & 1.47 & $15.03 \pm 3.26$ \\
\hline
\end{tabular}




\begin{tabular}{|c|c|c|c|c|c|c|}
\hline & $\begin{array}{l}\text { Bovine muscle } \\
\text { surrounded by } \\
\text { chicken skin }\end{array}$ & No & 100 & - & - & 4.4 \\
\hline Barbé et al. ${ }^{99}$ & $\begin{array}{l}\text { In vivo porcine } \\
\text { skin }\end{array}$ & No & - & - & - & 3 \\
\hline Zivanovic \& Davies ${ }^{107}$ & Polymer & No & - & 30 & - & 1.5 \\
\hline Saito \& Togawa ${ }^{108}$ & $\begin{array}{l}\text { In vivo rabbit } \\
\text { ear and vein }\end{array}$ & No & 2.5 & 15 & 0.4 & $0.18 \pm 0.04$ \\
\hline Kobayashi et al. ${ }^{103}$ & $\begin{array}{l}\text { Porcine } \\
\text { jugular vein }\end{array}$ & No & 5 & 20 & 1.36 & 0.52 \\
\hline Okuno et al. ${ }^{109}$ & $\begin{array}{l}\text { In vivo human } \\
\text { forearm skin } \\
\text { and median } \\
\text { vein }\end{array}$ & No & 15 & 15 & $\begin{array}{l}0.4 \\
0.8\end{array}$ & $\begin{array}{l}0.23 \pm 0.09 \\
0.64 \pm 0.23\end{array}$ \\
\hline
\end{tabular}

${ }^{a}$ Force peaks correspond to needle insertion and catheter insertion, respectively.

${ }^{b}$ Force peaks were obtained for different catheter materials, namely, PTFE and PUR.

The results are rather disparate. Indeed, different tissues were investigated, and the experimental conditions, such as the impact velocity, the angle insertion and the perforator diameter, also differed between studies. Nevertheless, the common denominator between the reviewed studies is the use of a needle during the tests.

The studies by Shergold \& Fleck ${ }^{105}$ and Okuno et al. ${ }^{109}$ are particularly notable. The authors performed in vivo tests on the ventral side of the forearm, providing insights into the forces needed to puncture skin at this site. Results reported by Okuno et al. are more interesting for the design of a realistic simulator for the antebrachial zone, as the forearm skin and median antebrachial vein were punctured in vivo. Eriksson et al. ${ }^{101}$ also punctured human skin and veins in vivo, but values for the observed measures were higher. A plausible explanation is that the epidermis is thicker on the dorsal surface of the hand than on the ventral forearm ${ }^{21}$, resulting in a higher puncture force because of the increased stiffness of the stratum corneum ${ }^{73}$. Another potential explanation is that the veins on the dorsal surface of the hand are more apparent, thus combining its stiffness with that of skin like a sandwich material.

\section{Materials mimicking human soft tissues}

As described above, numerous mechanical tests have been conducted on human skin to obtain a better understanding of the nature of this complex material, whereas mechanical properties of veins have been much less frequently investigated than arteries, which are the site affected in the majority of patients with vascular diseases. Regarding tissue-mimicking materials, currently, commercially available skin equivalents are mainly used to heal skin damage by protecting the skin from bacteria or to deliver drugs ${ }^{110}$. Therefore, the mechanical properties of these skin substitutes are not representative of human skin. Moreover, because the skin is a living tissue, the results are 
highly variable and possible ethical issues frequently prevent scientists from performing tests. Hence, numerous researchers have attempted to develop suitable synthetic skin substitutes that will enable them to perform more controlled and rapidly implemented experiments. Dąbrowska et al. ${ }^{111}$ provided an overview of the materials used in the literature to simulate the physical properties of human skin. Their review revealed very diverse materials because the development of each physical skin model is closely related to its application. For example, metals and textiles have been used to reproduce the thermal properties of skin and investigate its sweating phenomenon. The main tissue properties that must be reproduced for $\mathrm{PVCl}$ are the surface properties of skin and the mechanical properties of both the skin and the veins, which are, according to the aforementioned review, well mimicked by gelatinous substances, such as gelatin, agar and polyvinyl alcohol (PVA) gels, or by elastomers, such as silicones, polyurethanes and polyvinyl chloride (PVC). However, most gelatinous substances, which are biopolymers, tend to contain a high mass fraction of water $(>80 \%)$ making them unsuitable for long-term use because of the evaporation of their water content and eventual bacterial growth ${ }^{112}$. Therefore, we focused on articles testing chemically synthesized polymers, which are more stable and durable ${ }^{113}$, resulting in more suitable materials for long-term storage in the simulators used by medical schools or hospitals.

\subsection{Tissue-mimicking substitutes related to palpation and surface touch}

Elleuch et al. ${ }^{80}$ performed in vivo indentation and friction tests on the volar forearm of 3 women and compared the results with tests performed on silicone, which is usually used as a replica material, and a thermoplastic polyurethane elastomer (TPU). The effects of the loading speed and the applied normal load on the results of both types of tests were assessed. The friction coefficient of the TPU was comparable to skin; however, due to a high adhesive component in the contact, the friction coefficient of silicone was much higher. The Young's modulus of the elastomeric materials was several orders of magnitude higher than the skin.

Derler et al. ${ }^{45}$ measured the dynamic friction coefficient of skin and synthetic substitutes with a 3component dynamometer to capture the normal and tangential forces. Among the tested substitutes, a polyurethane-coated polyamide fleece commercially known as the artificial leather Lorica ${ }^{\circledR}$ Soft has a friction behavior comparable to dry skin; moreover, the friction coefficient of the cited material increases with the moisture content. This behavior is mainly attributed to a surface structure similar to skin; however, the Shore hardness value of this particular material was too high to represent the mechanical behavior of skin.

Morales-Hurtado et al. ${ }^{110}$ developed an epidermal skin equivalent by mixing hydrophobic polydimethylsiloxane (PDMS) with a premade mixture of a cross-linked hydrophilic PVA hydrogel with glutaraldehyde. After determining the appropriate mixture ratio, the authors developed a substitute for which the mechanical properties were able to be changed according to relative humidity, similar to the epidermis. Using a laser confocal microscope, a $13 \pm 2 \mu \mathrm{m}$ Ra was measured, which appears to be in the lower range of the results reported in the literature. Regarding the elastic modulus, Morales-Hurtado et al. ${ }^{110}$ performed indentation tests and reported an effective elastic modulus of $0.7 \mathrm{MPa}$ and $0.5 \mathrm{MPa}$ under dry and wet conditions, respectively, for a displacement increasing to $4.5 \mathrm{~mm}$. However, these results are one order of magnitude higher than the available results from the literature, more precisely for full thickness skin stiffnesses obtained from in vivo 
indentation tests. Currently, compared to the elastic modulus reported for the epidermis alone in the literature, the results appears to be in the lower range of values 8773114 .

Stricher et al. ${ }^{115}$ manufactured anisotropic PDMS membranes using an innovative technique based on controlled cross-linking mediated by UV-induced degradation.

Nachman \& Franklin ${ }^{116}$ developed a bilayer skin substitute by superimposing a hydrophilic silicone layer and a polyurethane gel layer with a Shore 00 hardness of 19, representing the epidermis and both the dermis and the hypodermis, respectively. As conventional silicone elastomers are hydrophobic, the authors modified the chosen silicone layer by adding strongly hydrophilic alphaolefin sulfonate to the mixture; thus, the material depended on humidity. Because the skin topography also exerts strong effects on the friction coefficient and roughness, the authors used an elastomer-based mold-making material to prepare a negative replica of the human skin texture from a forearm, which was used to mold the top surface of their artificial skin. A tribometer was used on the inner forearm of a 29-year-old woman to compare the friction coefficient and reduced elastic modulus. While the friction coefficient showed good correspondence under identical experimental conditions (dry and moist states), the reduced elastic modulus was three times greater than the results obtained from in vivo tests, which, according to the authors, is due to the lack of consideration of the stiffness of the top layer. Nevertheless, the obtained reduced elastic modulus of 30-35 kPa was consistent with the literature ${ }^{70}$.

Although no tribological tests were performed and gelatinous substances were used, the study by Chen et al. ${ }^{117}$ is worth mentioning. To our knowledge, these researchers are the first to develop a three-layer skin substitute with an embedded vessel phantom for which each component was mechanically tested and compared with published results obtained from human and porcine tissues. However, mechanical tests have not been performed on the multilayered structure. The authors added an antimicrobial agent to compensate for the time-dependent degradation of agar and gelatin, which has proven capable of maintaining stable mechanical properties over a 7-10 month period $^{118}$.

\subsection{Tissue-mimicking substitutes related to perforation}

Muthu ${ }^{119}$ performed tests on cadaver skin and on different polymers to identify a potential substitute and to obtain a better understanding of the mechanics of micro needle perforation for the transport of drug molecules through the skin. Based on his results and the study by Romanelli \& Falanga ${ }^{120}$, who measured skin induration on the leg with a hand-held type $O$ durometer, Muthu found that a silicone material with a Shore A hardness of 20 displayed a similar force vs. needle tip displacement to that of cadaver skin for micro perforation.

Chen et al. ${ }^{10}$ developed a computational model to simulate the mechanics of needle insertion into a blood vessel. Three situations that a practitioner might encounter during the puncture of a vein were simulated: a normal puncture when the axis of the needle matches the medial axis of the vein and a rolling or a rupture of the vein when the axes were not aligned to simulate patients with rolling or hardened veins. Chen et al. performed in vitro tests of vessel rolling and deformation using blood vessel phantoms to validate the numerical results. The vessels were half embedded in a support tissue formed from porcine gelatin, for which the mechanical properties were controlled to simulate dermis and hypodermis. According to the authors, a support tissue with a Young's modulus of $0.5 \mathrm{kPa}$ was sufficiently compliant to allow the vessel phantoms to roll. However, the mechanical parameters 
reported in the literature, which were used in their numerical simulation, were not adapted to their applications. Indeed, the parameters were based on data from suction experiments ${ }^{121}$ on skin and burst pressure, compliance and suture retention of saphenous veins and internal mammary arteries 122.

Wang et al. ${ }^{113}$ compared indentation and perforation measurements performed on different porcine tissues with an RTV (Room Temperature Vulcanization) two-component silicone material modified with different percentages of mineral oil. Using a 000-S durometer, the authors were able to assess the elastic moduli for both living and synthetic tissues. For perforation measurements, the tests consisted of an initial perforation characterized by a peak force followed by three insertions into the previously generated hole to assess the durability under repeated insertions. The peak force was decomposed into friction and cutting forces, the latter of which was obtained by subtracting the measured peak and friction forces. The addition of mineral oil into the mixture reduced the mechanical properties to a certain limit, which was equal to $30 \mathrm{wt}$. \%. However, the elastic modulus only exhibited slight changes following the inclusion of a higher percentage of mineral oil ( $40 \mathrm{wt}$. \%), whereas the perforation forces drastically decreased, resulting in a good correlation with the tested porcine tissues, particularly for tests performed perpendicularly to porcine muscle fibers. Moreover, the influence of cutting forces on the phantoms remained constant, regardless of the mineral oil percentage, indicating that only friction forces were reduced due to the lubricity of the mineral oil. At contents exceeding $40 \mathrm{wt}$. \% mineral oil, the silicone material became difficult to manufacture.

Finally, the average elastic modulus and peak force of the silicone materials that were most similar to in vivo tissues were $10.3 \mathrm{kPa}$ and $0.9 \mathrm{~N}$, respectively, thus ranking very well among in vivo measurements reported in the literature.

Soft PVC has also been investigated as a substitute to perform perforation tests ${ }^{123}$. A factorial design of experiments was established to study different factors influencing the mechanical properties of soft PVC. By varying the ratio of softener and PVC polymer solution, as well as the mass fraction of mineral oil, the authors were able to control the mechanical properties to approach in vivo values in terms of the compression elastic modulus and friction forces in ex vivo porcine tissues ${ }^{113}$.

\section{Discussion}

Although the sterilization phase is not included in the analysis of the mechanical loads applied to the skin, we remind the reader that this phase is very important to avoid complications such as phlebitis, infiltration, occlusion, local infection, and bloodstream infection ${ }^{124}$. Disinfectants must be used during the medical protocol, which may prevent the application of powder to artificially decrease friction. Therefore, a simulator that replicates the skin topography represents another method to obtain the aim of touch sensation. A study of the chemical and mechanical wear of the selected polymers must be conducted to ensure that the tribological properties will not be easily affected after repeated use by students and to define the lifespan of the selected materials following repeated punctures. The large vein thickness used in current simulators is likely meant to endow the polymer with "healing" properties to increase the lifespan of the simulator, which substantially decreases its representativeness. Current simulators also lack a compliant material in which the synthetic vessels will be embedded to allow them to roll, which is one challenge nurses must address when inserting a needle.

As perforation measurements are influenced by velocity and angle insertion ${ }^{94}$, the gesture of the practitioner during the puncture phase of PVCl must be analyzed. These measurements will then 
serve as experimental conditions under which suitable skin-like materials are tested with commonly used catheters. In vivo perforation tests performed on the ventral forearm reported in the literature lack information ${ }^{105}{ }^{109}$. Indeed, the results are only described as peak forces, without mentioning friction and cutting forces, which will likely impact the sensation of the practitioner during perforation. Additionally, the needle was not surrounded by a catheter, which has been proven to influence the puncture force curve ${ }^{101}{ }^{102}$. This observation suggests the need for in vivo perforation tests for the medical procedure being simulated. The same approach can be used for the palpation phase of the procedure. Nevertheless, the study by Okuno et al. should be considered reference data for the puncture phase, because in vivo results were obtained by a medical technician and therefore tissues were mechanically solicited under physiological conditions. Regarding indentation tests, none of the studies described here were performed by mechanically soliciting the tissues under physiological conditions. Moreover, the indenters' geometric shapes are known to exert a substantial effect on the results. An indenter with a curvature similar to a fingertip would be more adapted to reproduce the gesture of the practitioner. However, among the reviewed studies, the results reported by Pailler-Mattei et al. and Tran et al. should be used for a comparison with the results obtained from indentation tests performed on skin substitutes, as a high depth penetration was imposed.

Additionally, tissue substitutes are mainly validated by performing mechanical tests; however, this approach presents some limitations in terms of touch perception, which is highly subjective. Mechanically, the substitutes display a good correlation with human tissues, whereas touch perception may be completely different. The validation process should include a sensory evaluation that consists of training a panel of participants to become tactile experts to evaluate the properties of the products. An untrained panel can also be used; however, its discrimination ability is lower than a trained panel ${ }^{125}$. Tactile sensory evaluations have been widely used to evaluate packaging, cosmetic products or in the automotive industry ${ }^{126-128}$. For a medical simulator, the panel should include health professionals trained to perform the medical procedure in question. The sensory evaluation should then be performed to assess the surface, mechanical and perforation properties.

Finally, the question of the uniqueness of the $\mathrm{PVCl}$ simulator is raised. As skin properties are clearly influenced by sex and age, among many other factors, one PVCl simulator is obviously not sufficient to represent a unique real skin tissue that does not even exist. Therefore, an interesting question is how close to actual clinical practice is sufficient to learn a technique. An increase in the realism of simulators may not be needed to learn how to insert a catheter. However, the definition of realism and the collection of all existing data on skin for the application proposed here allow us to imagine different levels of difficulties for the PVCl simulator. Ultimately, the nurse instructors or the students training on the simulator themselves must determine which degree of realism is sufficient to enable the practitioner to be prepared for the first in vivo procedure.

\section{Conclusions}

We reviewed the available results published to date in the literature for research performed on skin and veins to be able to design a more realistic PVCl simulator than the simulators currently used by health care students. As shown throughout this review, the data on the tribology, indentation and perforation of human skin are quite extensive and scattered. Therefore, we decided to review 
articles that mainly describe data obtained from in vivo experiments performed on human forearm skin, the site at which peripheral catheters are often inserted. We also tried to identify studies involving experimental conditions similar to the physiological conditions of catheter insertion, thus facilitating the establishment of specifications for future skin substitutes. Then, we presented the strengths and weaknesses of different existing substitutes in regard to our specific aim.

Although this review primarily focused on the mechanical parameters that are useful for designing a realistic $\mathrm{PVCl}$ simulator, difficulties related to manufacturing process, cost and time were not discussed. Finally, future PVCl simulator prototypes must respond to the targeted mechanical parameters collected in this review, but above all, they will toned to be evaluated in an educational context with students and trained practitioners through a sensory analysis.

\section{Acknowledgments}

The authors would like to thank Patrick Attali, nurse instructor, for his insightful feedback about the $\mathrm{PVCl}$, as well as Yoann Lafon and Pr. Xavier Martin.

\section{Funding}

This research was supported by ANR 11 IDFI 0034 as part of the SAMSEI project.

\section{Conflict of interest}

The authors have no conflicts of interest to declare.

\section{Bibliography}

1. Maki DG, Kluger DM, Crnich CJ. The risk of bloodstream infection in adults with different intravascular devices: a systematic review of 200 published prospective studies. Mayo Clin Proc 2006; 81: 1159-1171.

2. Helm RE, Klausner JD, Klemperer JD, et al. Accepted but unacceptable: peripheral IV catheter failure. J Infus Nurs Off Publ Infus Nurses Soc 2015; 38: 189-203.

3. Frey AM. Success rates for peripheral i.v. insertion in a children's hospital. Financial implications. J Intraven Nurs Off Publ Intraven Nurses Soc 1998; 21: 160-165.

4. Jacobson AF, Winslow EH. Variables influencing intravenous catheter insertion difficulty and failure: an analysis of 339 intravenous catheter insertions. Heart Lung J Crit Care 2005; 34: 345-359.

5. Palefski SS, Stoddard GJ. The infusion nurse and patient complication rates of peripheral-short catheters. A prospective evaluation. J Intraven Nurs Off Publ Intraven Nurses Soc 2001; 24: 113-123.

6. Barton AJ, Danek G, Johns P, et al. Improving patient outcomes through CQI: vascular access planning. J Nurs Care Qual 1998; 13: 77-85.

7. Lininger RA. Pediatric peripheral i.v. insertion success rates. Pediatr Nurs 2003; 29: 351-354. 
8. Carr PJ, Rippey JCR, Cooke ML, et al. Development of a clinical prediction rule to improve peripheral intravenous cannulae first attempt success in the emergency department and reduce post insertion failure rates: the Vascular Access Decisions in the Emergency Room (VADER) study protocol. BMJ Open 2016; 6: e009196.

9. Balter ML, Chen Al, Maguire TJ, et al. The System Design and Evaluation of a 7-DOF ImageGuided Venipuncture Robot. IEEE Trans Robot Publ IEEE Robot Autom Soc 2015; 31: 10441053.

10. Chen Al, Balter ML, Maguire TJ, et al. Real-time Needle Steering in Response to Rolling Vein Deformation by a 9-DOF Image-Guided Autonomous Venipuncture Robot. Proc IEEERSJ Int Conf Intell Robots Syst IEEERSJ Int Conf Intell Robots Syst 2015; 2015: 2633-2638.

11. Al-Elq AH. Simulation-based medical teaching and learning. J Fam Community Med 2010; 17: 35-40.

12. Seropian MA, Brown K, Gavilanes JS, et al. Simulation: not just a manikin. J Nurs Educ 2004; 43: 164-169.

13. Maran NJ, Glavin RJ. Low- to high-fidelity simulation - a continuum of medical education? Med Educ 2003; 37 Suppl 1: 22-28.

14. Brett PN, Parker TJ, Harrison AJ, et al. Simulation of resistance forces acting on surgical needles. Proc Inst Mech Eng [H] 1997; 211: 335-347.

15. Vaughan N, Dubey VN, Wee MYK, et al. A review of epidural simulators: Where are we today? Med Eng Phys 2013; 35: 1235-1250.

16. Goolsby CA, Goodwin TL, Vest RM. Hybrid simulation improves medical student procedural confidence during EM clerkship. Mil Med 2014; 179: 1223-1227.

17. Wilfong DN, Falsetti DJ, McKinnon JL, et al. The effects of virtual intravenous and patient simulator training compared to the traditional approach of teaching nurses: a research project on peripheral i.v. catheter insertion. J Infus Nurs Off Publ Infus Nurses Soc 2011; 34: 55-62.

18. Keleekai NL, Schuster CA, Murray CL, et al. Improving Nurses' Peripheral Intravenous Catheter Insertion Knowledge, Confidence, and Skills Using a Simulation-Based Blended Learning Program. Simul Healthc 2016; 11: 376-384.

19. Gray H. Anatomy of the Human Body. Lea \& Febiger. Bartleby.com, 2000, www.bartleby.com/107/ (1918).

20. Agache P. Physiologie de la peau et explorations fonctionnelles cutanées. Paris: Tec \& Doc Lavoisier, 2000.

21. Lee Y, Hwang K. Skin thickness of Korean adults. Surg Radiol Anat 2002; 24: 183-189.

22. Hwang K, Kim H, Kim DJ. Thickness of skin and subcutaneous tissue of the free flap donor sites: A histologic study. Microsurgery 2016; 36: 54-58.

23. Hendriks FM, Brokken D, van Eemeren JTWM, et al. A numerical-experimental method to characterize the non-linear mechanical behaviour of human skin. Skin Res Technol Off J Int Soc Bioeng Skin ISBS Int Soc Digit Imaging Skin ISDIS Int Soc Skin Imaging ISSI 2003; 9: 274-283. 
24. Diridollou $S$, Berson $M$, Vabre $V$, et al. An in vivo method for measuring the mechanical properties of the skin using ultrasound. Ultrasound Med Biol 1998; 24: 215-224.

25. Escoffier C, de Rigal J, Rochefort A, et al. Age-related mechanical properties of human skin: an in vivo study. J Invest Dermatol 1989; 93: 353-357.

26. Gennisson JL, Baldeweck T, Tanter M, et al. Assessment of elastic parameters of human skin using dynamic elastography. IEEE Trans Ultrason Ferroelectr Freq Control 2004; 51: 980-989.

27. Maiti R, Gerhardt L-C, Lee ZS, et al. In vivo measurement of skin surface strain and sub-surface layer deformation induced by natural tissue stretching. J Mech Behav Biomed Mater 2016; 62: 556-569.

28. Kiray A, Ergür I, Tayefi $\mathrm{H}$, et al. Anatomical evaluation of the superficial veins of the upper extremity as graft donor source in microvascular reconstructions: a cadaveric study. Acta Orthop Traumatol Turc 2013; 47: 405-410.

29. Shima $\mathrm{H}$, Ohno K, Michi K, et al. An anatomical study on the forearm vascular system. J CranioMaxillo-fac Surg Off Publ Eur Assoc Cranio-Maxillo-fac Surg 1996; 24: 293-299.

30. Irfan H, Ooi GS, Kyin MM, et al. Revealing Maximal Diameter of Upper Limb Superficial Vein with an Elevated Environmental Temperature. Int J Chronic Dis 2016; 2016: 8096473.

31. Zharov VP, Ferguson S, Eidt JF, et al. Infrared imaging of subcutaneous veins. Lasers Surg Med 2004; 34: 56-61.

32. Nishidate I, Maeda T, Aizu Y, et al. Visualizing depth and thickness of a local blood region in skin tissue using diffuse reflectance images. J Biomed Opt 2007; 12: 054006.

33. Payne BP, Venugopalan V, Mikić BB, et al. Optoacoustic tomography using time-resolved interferometric detection of surface displacement. J Biomed Opt 2003; 8: 273-280.

34. Kawazu K, Kai M, Koike K, et al. Study of Favorable Feel Paint-Quantifying the Sense of Touch for Painted Panels. SAE Trans 2000; 109: 782-787.

35. Derler S, Gerhardt L-C. Tribology of Skin: Review and Analysis of Experimental Results for the Friction Coefficient of Human Skin. Tribol Lett 2012; 45: 1-27.

36. Pailler-Mattei C, Nicoli S, Pirot F, et al. A new approach to describe the skin surface physical properties in vivo. Colloids Surf B Biointerfaces 2009; 68: 200-206.

37. Adams MJ, Briscoe BJ, Johnson SA. Friction and lubrication of human skin. Tribol Lett 2007; 26: 239-253.

38. Sivamani RK, Goodman J, Gitis NV, et al. Friction coefficient of skin in real-time. Skin Res Technol Off J Int Soc Bioeng Skin ISBS Int Soc Digit Imaging Skin ISDIS Int Soc Skin Imaging ISSI 2003; 9: 235-239.

39. Sivamani RK, Wu GC, Gitis NV, et al. Tribological testing of skin products: gender, age, and ethnicity on the volar forearm. Skin Res Technol Off J Int Soc Bioeng Skin ISBS Int Soc Digit Imaging Skin ISDIS Int Soc Skin Imaging ISSI 2003; 9: 299-305. 
40. Egawa M, Oguri M, Hirao $T$, et al. The evaluation of skin friction using a frictional feel analyzer. Skin Res Technol Off J Int Soc Bioeng Skin ISBS Int Soc Digit Imaging Skin ISDIS Int Soc Skin Imaging ISSI 2002; 8: 41-51.

41. Cua AB, Wilhelm KP, Maibach HI. Skin surface lipid and skin friction: relation to age, sex and anatomical region. Skin Pharmacol Off J Skin Pharmacol Soc 1995; 8: 246-251.

42. Elsner P, Wilhelm D, Maibach HI. Frictional properties of human forearm and vulvar skin: influence of age and correlation with transepidermal water loss and capacitance. Dermatologica 1990; 181: 88-91.

43. Zhu YH, Song SP, Luo W, et al. Characterization of skin friction coefficient, and relationship to stratum corneum hydration in a normal Chinese population. Skin Pharmacol Physiol 2011; 24: 81-86.

44. Cua AB, Wilhelm KP, Maibach HI. Frictional properties of human skin: relation to age, sex and anatomical region, stratum corneum hydration and transepidermal water loss. Br J Dermatol 1990; 123: 473-479.

45. Derler S, Schrade U, Gerhardt L-C. Tribology of human skin and mechanical skin equivalents in contact with textiles. Wear 2007; 263: 1112-1116.

46. Gupta AB, Haldar B, Bhattacharya M. A Simple Device For Measuring Skin Friction. Indian J Dermatol 1995; 40: 116.

47. Zhang M, Mak AF. In vivo friction properties of human skin. Prosthet Orthot Int 1999; 23: 135141.

48. El-Shimi AF. In vivo skin friction measurements. J Soc CosmetChem 1977; 28: 37-51.

49. Egawa $\mathrm{M}$, Oguri $\mathrm{M}$, Kuwahara $\mathrm{T}$, et al. Effect of exposure of human skin to a dry environment. Skin Res Technol Off J Int Soc Bioeng Skin ISBS Int Soc Digit Imaging Skin ISDIS Int Soc Skin Imaging ISSI 2002; 8: 212-218.

50. Jacobi U, Chen M, Frankowski G, et al. In vivo determination of skin surface topography using an optical 3D device. Skin Res Technol Off J Int Soc Bioeng Skin ISBS Int Soc Digit Imaging Skin ISDIS Int Soc Skin Imaging ISSI 2004; 10: 207-214.

51. Kampf G, Ennen J. Regular use of a hand cream can attenuate skin dryness and roughness caused by frequent hand washing. BMC Dermatol 2006; 6: 1.

52. Li L, Mac-Mary S, Marsaut D, et al. Age-related changes in skin topography and microcirculation. Arch Dermatol Res 2006; 297: 412-416.

53. Bloemen MCT, van Gerven MS, van der Wal MBA, et al. An objective device for measuring surface roughness of skin and scars. J Am Acad Dermatol 2011; 64: 706-715.

54. Luther N, Darvin ME, Sterry W, et al. Ethnic differences in skin physiology, hair follicle morphology and follicular penetration. Skin Pharmacol Physiol 2012; 25: 182-191.

55. Kottner J, Schario M, Garcia Bartels N, et al. Comparison of two in vivo measurements for skin surface topography. Skin Res Technol Off J Int Soc Bioeng Skin ISBS Int Soc Digit Imaging Skin ISDIS Int Soc Skin Imaging ISSI 2013; 19: 84-90. 
56. Trojahn C, Dobos G, Richter C, et al. Measuring skin aging using optical coherence tomography in vivo: a validation study. J Biomed Opt 2015; 20: 045003.

57. Comaish S, Bottoms E. The skin and friction: deviations from Amonton's laws, and the effects of hydration and lubrication. Br J Dermatol 1971; 84: 37-43.

58. Chaiyakunapruk N, Veenstra DL, Lipsky BA, et al. Chlorhexidine Compared with PovidoneIodine Solution for Vascular Catheter-Site Care: A Meta-Analysis. Ann Intern Med 2002; 136: 792.

59. Caldeira D, David C, Sampaio C. Skin antiseptics in venous puncture-site disinfection for prevention of blood culture contamination: systematic review with meta-analysis. $J$ Hosp Infect 2011; 77: 223-232.

60. Fung YC. Biomechanics: Mechanical Properties of Living Tissues. Springer Science \& Business Media, 2013.

61. Holzapfel GA. Biomechanics of soft tissue. Handb Mater Behav Models 2001; 3: 1049-1063.

62. Dunn MG, Silver FH. Viscoelastic Behavior of Human Connective Tissues: Relative Contribution of Viscous and Elastic Components. Connect Tissue Res 1983; 12: 59-70.

63. Daly CH. Biomechanical properties of dermis. J Invest Dermatol 1982; 79 Suppl 1: 17s-20s.

64. Langer K. On the anatomy and physiology of the skin. Br J Plast Surg 1978; 31: 3-8.

65. Wilkes GL, Brown IA, Wildnauer RH. The biomechanical properties of skin. CRC Crit Rev Bioeng 1973; 1: 453-495.

66. Gahagnon S, Mofid Y, Josse G, et al. Skin anisotropy in vivo and initial natural stress effect: a quantitative study using high-frequency static elastography. J Biomech 2012; 45: 2860-2865.

67. North JF, Gibson F. Volume compressibility of human abdominal skin. J Biomech 1978; 11: 203-207.

68. Vossoughi J, Vaishnav RN. Comments on the paper 'Volume Compressibility of Human Abdominal Skin'. J Biomech 1979; 12: 481.

69. Payne PA. Measurement of properties and function of skin. Clin Phys Physiol Meas 1991; 12: 105.

70. Kuilenburg J van, Masen MA, Heide E van der. Contact modelling of human skin: What value to use for the modulus of elasticity? Proc Inst Mech Eng Part J J Eng Tribol 2013; 227: 349361.

71. Zheng Y, Mak AF, Lue B. Objective assessment of limb tissue elasticity: development of a manual indentation procedure. J Rehabil Res Dev 1999; 36: 71-85.

72. livarinen JT, Korhonen RK, Julkunen P, et al. Experimental and computational analysis of soft tissue mechanical response under negative pressure in forearm. Skin Res Technol Off J Int Soc Bioeng Skin ISBS Int Soc Digit Imaging Skin ISDIS Int Soc Skin Imaging ISSI 2013; 19: e356-365. 
73. Pailler-Mattei C, Pavan S, Vargiolu R, et al. Contribution of stratum corneum in determining bio-tribological properties of the human skin. Wear 2007; 263: 1038-1043.

74. Dikstein S, Hartzshtark A. What does low pressure indentometry measure ? Artzliche Kosmetol 1983; 13: 327-328.

75. Silver FH, Freeman JW, DeVore D. Viscoelastic properties of human skin and processed dermis. Skin Res Technol Off J Int Soc Bioeng Skin ISBS Int Soc Digit Imaging Skin ISDIS Int Soc Skin Imaging ISSI 2001; 7: 18-23.

76. Pailler-Mattei $\mathrm{C}$, Bec S, Zahouani $\mathrm{H}$. In vivo measurements of the elastic mechanical properties of human skin by indentation tests. Med Eng Phys 2008; 30: 599-606.

77. Abellan $\mathrm{M}-\mathrm{A}$, Ayadh $\mathrm{M}$, Feulvarch $\mathrm{E}$, et al. Caractérisation des paramètres mécaniques de la peau humaine jeune in vivo par essais d'indentation sans contact. 22éme Congrès Fr Mécanique.

78. Tran $\mathrm{H}$, Charleux F, Ehrlacher A, et al. Propriétés mécaniques multi-couches de la peau humaine in vivo. Colloq Natl En Calc Struct.

79. Tran HV, Charleux F, Rachik M, et al. In vivo characterization of the mechanical properties of human skin derived from MRI and indentation techniques. Comput Methods Biomech Biomed Engin 2007; 10: 401-407.

80. Elleuch K, Elleuch R, Zahouani H. Comparison of elastic and tactile behavior of human skin and elastomeric materials through tribological tests. Polym Eng Sci 2006; 46: 1715-1720.

81. Pailler-Mattei C, Debret R, Vargiolu R, et al. In vivo skin biophysical behaviour and surface topography as a function of ageing. J Mech Behav Biomed Mater 2013; 28: 474-483.

82. Delalleau A, Josse $\mathrm{G}$, Lagarde J-M, et al. Characterization of the mechanical properties of skin by inverse analysis combined with the indentation test. J Biomech 2006; 39: 1603-1610.

83. Jachowicz J, McMullen R, Prettypaul D. Indentometric analysis of in vivo skin and comparison with artificial skin models. Skin Res Technol 2007; 13: 299-309.

84. Zahouani H, Pailler-Mattei C, Sohm B, et al. Characterization of the mechanical properties of a dermal equivalent compared with human skin in vivo by indentation and static friction tests. Skin Res Technol Off J Int Soc Bioeng Skin ISBS Int Soc Digit Imaging Skin ISDIS Int Soc Skin Imaging ISSI 2009; 15: 68-76.

85. Wildnauer RH, Bothwell JW, Douglass AB. Stratum Corneum Biomechanical Properties I. Influence of Relative Humidity on Normal and Extracted Human Stratum Corneum. J Invest Dermatol 1971; 56: 72-78.

86. Oliver WC, Pharr GM. An improved technique for determining hardness and elastic modulus using load and displacement sensing indentation experiments. J Mater Res 1992; 7: 15641583.

87. Geerligs $M$, van Breemen $L$, Peters $G$, et al. In vitro indentation to determine the mechanical properties of epidermis. J Biomech 2011; 44: 1176-1181. 
88. Holzapfel GA, Gasser TC, Ogden RW. A New Constitutive Framework for Arterial Wall Mechanics and a Comparative Study of Material Models. J Elast Phys Sci Solids 2000; 61: 1-48.

89. Ogden RW. Large Deformation Isotropic Elasticity: On the Correlation of Theory and Experiment for Compressible Rubberlike Solids. Proc R Soc Lond Math Phys Eng Sci 1972; 328: 567-583.

90. Joodaki H, Panzer MB. Skin mechanical properties and modeling: A review. Proc Inst Mech Eng [H] 2018; 232: 323-343.

91. Knight B. The dynamics of stab wounds. Forensic Sci 1975; 6: 249-255.

92. Green MA. Stab Wound Dynamics-A Recording Technique for Use in Medico-Legal Investigations. J Forensic Sci Soc 1978; 18: 161-163.

93. Figge FHJ, Barnett DJ. Anatomic evaluation of a jet injection instrument designed to minimize pain and inconvenience of parenteral therapy. Am Pract Dig Treat 1948; 3: 197-206.

94. Shergold OA, Fleck NA. Mechanisms of deep penetration of soft solids, with application to the injection and wounding of skin. Proc R Soc Lond Math Phys Eng Sci 2004; 460: 3037-3058.

95. Frick TB, Marucci DD, Cartmill JA, et al. Resistance forces acting on suture needles. J Biomech 2001; 34: 1335-1340.

96. Heverly M, Dupont $\mathrm{P}$, Triedman J. Trajectory Optimization for Dynamic Needle Insertion. In: Proceedings of the 2005 IEEE International Conference on Robotics and Automation. 2005, pp. 1646-1651.

97. Mahvash M, Dupont PE. Mechanics of dynamic needle insertion into a biological material. IEEE Trans Biomed Eng 2010; 57: 934-943.

98. Okamura AM, Simone C, O'Leary MD. Force modeling for needle insertion into soft tissue. IEEE Trans Biomed Eng 2004; 51: 1707-1716.

99. Barbé L, Bayle B, de Mathelin M, et al. Needle insertions modeling: Identifiability and limitations. Biomed Signal Process Control 2007; 2: 191-198.

100. Maurin B, Barbe L, Bayle B, et al. In vivo study of forces during needle insertions. In: Perspective in Image-Guided Surgery. WORLD SCIENTIFIC, pp. 415-422.

101. Eriksson E, Larsson N, Nitescu P, et al. Penetration forces in cannulation of the dorsal veins of the hand: I. A comparison between polyurethane (Insyte ${ }^{\circledR}$ ) and polytetrafluoroethylene (Venflon ${ }^{\circledR}$ ) cannulae. Acta Anaesthesiol Scand 1991; 35: 306-314.

102. Suzuki T, Tanaka A, Fukuyama $H$, et al. Differences in penetration force of intravenous catheters: effect of grinding methods on inner needles of intravenous catheters. Tokai J Exp Clin Med 2004; 29: 175-181.

103. Kobayashi $\mathrm{Y}$, Hamano $\mathrm{R}$, Watanabe $\mathrm{H}$, et al. Use of puncture force measurement to investigate the conditions of blood vessel needle insertion. Med Eng Phys 2013; 35: 684-689.

104. Abolhassani N, Patel R, Moallem M. Experimental study of robotic needle insertion in soft tissue. Int Congr Ser 2004; 1268: 797-802. 
105. Shergold OA, Fleck NA. Experimental investigation into the deep penetration of soft solids by sharp and blunt punches, with application to the piercing of skin. J Biomech Eng 2005; 127: 838-848.

106. Podder TK, Sherman J, Clark DP, et al. Evaluation of robotic needle insertion in conjunction with in vivo manual insertion in the operating room. In: ROMAN 2005. IEEE International Workshop on Robot and Human Interactive Communication, 2005. 2005, pp. 66-72.

107. Zivanovic A, Davies BL. A robotic system for blood sampling. IEEE Trans Inf Technol Biomed Publ IEEE Eng Med Biol Soc 2000; 4: 8-14.

108. Saito $\mathrm{H}$, Togawa $\mathrm{T}$. Detection of needle puncture to blood vessel using puncture force measurement. Med Biol Eng Comput 2005; 43: 240-244.

109. Okuno D, Togawa $\mathrm{T}$, Saito $\mathrm{H}$, et al. Development of an automatic blood sampling system: control of the puncturing needle by measuring forces. In: Proceedings of the 20th Annual International Conference of the IEEE Engineering in Medicine and Biology Society. Vol.20 Biomedical Engineering Towards the Year 2000 and Beyond (Cat. No.98CH36286). 1998, pp. 1811-1812 vol.4.

110. Morales-Hurtado M, Zeng X, Gonzalez-Rodriguez $P$, et al. A new water absorbable mechanical Epidermal skin equivalent: The combination of hydrophobic PDMS and hydrophilic PVA hydrogel. J Mech Behav Biomed Mater 2015; 46: 305-317.

111. Dąbrowska A. K., Rotaru G.-M., Derler S., et al. Materials used to simulate physical properties of human skin. Skin Res Technol 2015; 22: 3-14.

112. Pogue BW, Patterson MS. Review of tissue simulating phantoms for optical spectroscopy, imaging and dosimetry. J Biomed Opt 2006; 11: 041102.

113. Wang $\mathrm{Y}$, Tai BL, $\mathrm{Yu} \mathrm{H}$, et al. Silicone-Based Tissue-Mimicking Phantom for Needle Insertion Simulation. J Med Devices 2014; 8: 021001-021001-7.

114. Yuan $Y$, Verma R. Measuring microelastic properties of stratum corneum. Colloids Surf $B$ Biointerfaces 2006; 48: 6-12.

115. Stricher A, Rinaldi RG, Machado G, et al. Light-Induced Bulk Architecturation of PDMS Membranes. Macromol Mater Eng 2016; 301: 1151-1157.

116. Nachman M, Franklin SE. Artificial Skin Model simulating dry and moist in vivo human skin friction and deformation behaviour. Tribol Int 2016; 97: 431-439.

117. Chen Al, Balter ML, Chen MI, et al. Multilayered tissue mimicking skin and vessel phantoms with tunable mechanical, optical, and acoustic properties. Med Phys 2016; 43: 3117-3131.

118. Madsen EL, Hobson MA, Shi $\mathrm{H}$, et al. Tissue-mimicking agar/gelatin materials for use in heterogeneous elastography phantoms. Phys Med Biol 2005; 50: 5597-5618.

119. Muthu J. Mechanics of silicon micro needle penetration in human cadaver skin and skin substitutes. Theses Diss, http://preserve.lehigh.edu/etd/972 (2007).

120. Romanelli M, Falanga V. Use of a durometer to measure the degree of skin induration in lipodermatosclerosis. J Am Acad Dermatol 1995; 32: 188-191. 
121. Hendriks FM, Brokken D, Oomens CWJ, et al. The relative contributions of different skin layers to the mechanical behavior of human skin in vivo using suction experiments. Med Eng Phys 2006; 28: 259-266.

122. Konig G, McAllister TN, Dusserre N, et al. Mechanical properties of completely autologous human tissue engineered blood vessels compared to human saphenous vein and mammary artery. Biomaterials 2009; 30: 1542-1550.

123. Li W, Belmont B, Shih A. Design and Manufacture of Polyvinyl Chloride (PVC) Tissue Mimicking Material for Needle Insertion. Procedia Manuf 2015; 1: 866-878.

124. Bernatchez SF. Care of Peripheral Venous Catheter Sites: Advantages of Transparent Film Dressings Over Tape and Gauze. J Assoc Vasc Access 2014; 19: 256-261.

125. Losó V, Gere A, Györey A, et al. Comparison of the performance of a trained and an untrained sensory panel on sweetcorn varieties with the PanelCheck software. Appl Stud Agribus Commer 2012; 1-2: 77-83.

126. Shao $F$, Chen X-J, Barnes $C J$, et al. A novel tactile sensation measurement system for qualifying touch perception. Proc Inst Mech Eng [H] 2010; 224: 97-105.

127. Crochemore S, Nesa D, Couderc S. Analyse sensorielle des matériaux d'habitacle automobile : toucher/vision. Tech Ing Chapitre AM 3292 Éditions TI 2004; 1-16.

128. Gilbert L. Caractérisation physico-chimique et sensorielle d'ingrédients cosmétiques: une approche méthodologique. phdthesis, Université du Havre, https://tel.archivesouvertes.fr/tel-00956601/document (2012, accessed 25 July 2017). 